\title{
TOWARDS AN ETHICAL RELATION TO THE NONHUMAN OTHER: DECONSTRUCTION, VEGANISM AND THE LAW
}

\author{
JAN-HARM DE VILLIERS*
}

\begin{abstract}
This article explores the ethical significance of deconstruction for law and advances veganism as a form of deconstruction that exposes and resists the anthropocentric character of social and legal configurations. The article engages with Jacques Derrida's project of deconstructing the (human) subject and draws on Drucilla Cornell's reconception of deconstruction as the philosophy of the limit. By examining the philosophical foundations of justice and deconstruction, the article exposes justice as the limit to a system of law and investigates the capacity of deconstruction to advance the ethical relation (to the nonhuman Other).
\end{abstract}

Justice? - you get justice in the next world, in this world, you have the law. ${ }^{1}$

\section{INTRODUCTION}

To assert that law and justice are not synonyms is no longer a controversial statement. The impotence of a system of positive law, as a mechanism to bring about a realm of even-handedness, has been widely illustrated and criticised. ${ }^{2}$ It was believed, not too long ago, that blacks were naturally born into a destiny of slavery, ${ }^{3}$ that women were physiologically and psychologically inferior and lesser beings than their male counterparts ${ }^{4}$ and that homosexuality, like cancer, was a disease that necessitated medical treatment. ${ }^{5}$ Not surprisingly, the law reflected these dogmas and by doing so engaged in a process of 'othering', by creating a protagonist-antagonist dualism and ultimately facilitating subordination. Laws relating to animals are also a direct manifestation of the philosophical presuppositions that underpin the way we perceive the nonhuman Other. What is needed, is a deconstruction of the system that fails to embrace that which is other to the system. In the first part of this article, I examine the philosophical foundations of and reciprocation between justice and deconstruction. Drawing on Drucilla Cornell's reconception of

LLM (Legal History, Comparative Law and Legal Philosophy) student under the guidance of Prof Karin van Marle, University of Pretoria. An abridged version of this article was delivered at The Society of Law Teachers of Southern Africa Conference in 2011.

$1 \quad$ W Gaddis A Frolic of his Own (1994) 1.

2 L Fuller 'Positivism and Fidelity to Law - A Reply to Professor Hart' (1958) 71 Harvard LR 630; A Hutchinson 'A Postmodern's Hart: Taking Rules Sceptically' (1995) 58 The Modern LR 788.

3 J Walvin Questioning Slavery (1996).

4 JS Mill The Subjection of Women (1869).

5 J D’Emiloi Sexual Politics, Sexual Communities 2 ed (1998). 
deconstruction as the philosophy of the limit, I illustrate the ethical significance of deconstruction for law in the second part. Relying on this notion of ethics, I finally demonstrate the deconstructive capacity of veganism and argue that veganism plays an important role in exposing and resisting anthropocentric configurations that perpetuate the subservient position of the nonhuman Other.

\section{Deconstruction AND THE LAW}

A search for and demand of justice is often accompanied by the problematic (and ultimately unattainable) task of defining justice. The inevitable certainty of pluralism and consequential challenge of identifying just substantive principles, force us to confront a reality wherein my ideal of justice will more often than not differ from, if not directly rival, that of my neighbour. But as Jacques Derrida reminds us, justice is a transcendent, incalculable experience and consequently 'one cannot speak directly about justice, thematize or objectivise justice, say "this is just", and even less "I am just", without immediately betraying justice, if not law, ${ }^{6}$ Subscription to this insight can however generate noteworthy concerns: If we are not able to recognise and concretise certain minimal standards as just, what are we (or should we be) striving for? Is an ethical critiquing of law not an exercise in futility, a postponement of the inevitability of equating justice to law? Such reasoning is however clearly not in accord with Derrida's insistence on reserving 'the possibility of a justice, indeed of a law that not only exceeds or contradicts law but also, perhaps, has no relation to law, or maintains such a strange relation to it that it may just as well demand law as exclude it":

This excess of justice over law and calculation, this overflowing of the unpresentable over the determinable, cannot and should not serve as an alibi for staying out of juridico-political battles, within an institution or a state, between institutions or states. ${ }^{8}$

Derrida's fundamental argument that justice exceeds law is based on Michel de Montaigne's insight (in turn followed by Blaise Pascal) into the naissance of the law. Law, not originating from justice or reason, is built on custom. That, according to Montaigne, is the 'mystical foundations of the authority of laws':

Custom creates the whole of equity, for the simple reason that it is accepted. It is the mystical foundation of its authority. Whoever carries it back to first principles destroys it. ${ }^{9}$

Montaigne argues that law has not been constructed in a way that allows for the embodiment of justice. We abide by the law not 'because they are just, but because they have authority'. ${ }^{10}$ Here, I deliberately use the word 'constructed', as the notion of law as a self-generating construct propelled by inherent

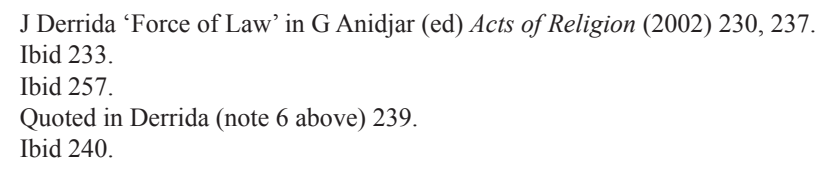


force, is fundamental to Derrida's insistence that the law is deconstructable. Employing the idiomatic expression 'to enforce the law' as point of departure, Derrida exposes the inevitable force that lies at the core of law. Whilst there are certainly laws that are not enforced, "there is no law without force, whether this force be direct or indirect, physical or symbolic, exterior or interior ....11 Without this force, any system's claim to be law would be redundant. This act of force central to the genesis of any legal system, endow the system with legitimacy. Since this constitutive force 'cannot by definition rest on anything but themselves, they are themselves a violence without ground. This is not to say that they are in themselves unjust, in the sense of "illegal" or "illegitimate". They are neither legal nor illegal in their founding moment'." By understanding that the law is primarily 'a fictional creation which selfperpetuates' and that there is no higher charge behind law, we can in turn understand that any attempt to conflate justice and positive law will inevitably result in naive legal positivism - a falsely held belief that justice can be found within the rights and remedies provided by an existing legal system. ${ }^{13}$ We can never completely attain justice by merely imparting a decision that is in accord with legal rules. Justice, as we will later see, is the limit to any legal system. Here, it is worth noting the ethical dimension to Derrida's deconstructive thought. By exposing the mythological structure underlying the authority of law, he accentuates the risk involved in safeguarding existing ideals as unquestionable truth. ${ }^{14}$

Before I turn to an analysis of Derrida's conceptualisation of Justice as Aporia, I would like to highlight a nexus between justice and deconstruction that Derrida evokes in Force of Law, namely the potential of deconstruction to destabilise the (arbitrarily constructed) limits that we erect to lead us in ascertaining which entities are worthy of being subjects of justice. History bears witness to numerous examples of marginalisation, and the focus of our concern for justice continues to be limited. Derrida argues that the violence of injustice is only applicable to humans, more specifically 'man as a speaking animal': ${ }^{15}$

$[\mathrm{O}]$ ne would not speak of injustice or violence toward an animal, even less toward a vegetable or a stone. An animal can be made to suffer, but one would never say, in a sense said to be proper, that it is a wronged subject, the victim of a crime, of a murder, of a rape or a theft, of a perjury. ${ }^{16}$

The exclusion of groups deemed inferior, Derrida argues, is however not restricted to nonhumans, as "there are still many "subjects" among humankind who are not recognised as subjects and who receive this animal treatment'.

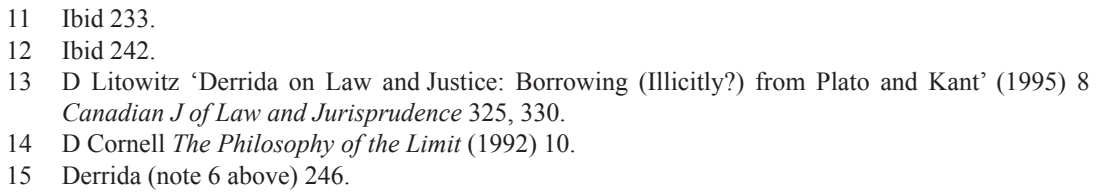


The barrier between those worthy of justice ('subjects of justice') and those not worthy ('non-subjects of justice') is thus unstable.

But what is the significance of identifying and exposing this (unstable) anthropocentric barrier that excludes the nonhuman animal from our sphere of concern for justice? This generates the opportunity for animal liberation scholars to deconstruct the barrier and challenge the exclusion of nonhumans as possible subjects of justice, as membership to a specific species should not be the decisive criterion granting moral citizenship to a subject. ${ }^{19}$ The potential of deconstruction to challenge these barriers embodies the corollary of re-setting the boundaries and, ultimately, ethically embracing the nonhuman Other. As Derrida argues:

[B]y deconstructing the partitions that institute the human subject (preferably and paradigmatically the adult male, rather than the woman, child, or animal) at the measure of the just and the unjust, one does not necessarily lead toward injustice, nor to effacement of an opposition between just and unjust but, in the name of a demand more insatiable than justice, leads perhaps to a reinterpretation of the whole apparatus of limits within which a history and a culture have been able to confine their criteriology. ${ }^{20}$

\section{(a) Conceptualising justice as aporia}

For Derrida, the very notion of justice embodies impossibility, a set of aporias that cannot be dissolved without paradoxicalising justice. This impossibility, as I have already argued, should not hinder our struggle for justice. We always owe justice to the Other and although this 'incalculable' demand can never be satisfied, the strive for justice nevertheless imposes a limitless responsibility, a 'bottomless duty to the Other'.

Derrida articulates three unsurpassable aporias to formulate his argument that justice is 'the experience that we are unable to experience'. The first aporia, the epokhē of the rule, delineates the impossibility accompanying any attempt to generate a just outcome to a scenario whilst also adhering to prescribed legal doctrine. To act justly, according to Derrida, one must necessarily be free, because 'one will not say of a being without freedom, or at least of one who is not free in a given act, that its decision is just or unjust'. ${ }^{22}$ A judge acting within the parameters of the law is however caught in a paradox: bound by rules and precedent on the one hand, the individualism of each case requires a de novo approach on the other, 'an absolutely unique interpretation which no existing coded rule can or ought to guarantee absolutely'. ${ }^{23}$ Monotonous adherence to and application of a rule cannot be equated to making a just decision, or even any decision.

J Balkin 'Transcendental Deconstruction, Transcendent Justice' (1994) 92 Michigan LR 1131, 1143 .

19 For an exposition of speciesism and the belief that only human life in sacrosanct, see P Singer Animal Liberation (2009) 18-23.

20 Derrida (note 6 above) 247.

21 Litowitz (note 13 above) 328.

22 Derrida (note 6 above) 251.

23 Ibid. 
To obtain justice through law, the judge needs to simultaneously judge the law, and judge by means of the law. A just decision will 'be both regulated and without regulation', it will 'preserve the law and also destroy or suspend it enough to have to reinvent it in each case'. ${ }^{24}$ To act in conformity with a legal principle might result in a decision that is unjust, whilst a just outcome might have no grounding in law. Thus, we clearly see 'justice run up against the limitations of law, and law run up against the impossibility of justice'. ${ }^{25}$

The second aporia is absorbedly related to the first and reveals the paradoxical relation between (a decision following the) law and justice. The 'haunting of the undecidable', which is caught in every legal decision, demarcates decision-making with calculation and illustrates why justice cannot exist with or without a decision. This undecidability is more than the mere pressure facing a judge when confronted with two or more decisions, it represents the experience of being caught in an unsurpassable moment of undecidability whilst taking cognisance of legal rules.

We need to clearly distinguish decision-making from calculation, 'for if calculation is calculation, the decision to calculate is not of the order of the calculable, and it must not be so, ${ }^{26}$ Whilst a decision not passing 'the test and ordeal of the undecidable' can never be a free decision, but only 'the programmable application ... of a calculable process', it is not possible to establish whether the judge went through this test and ordeal before rendering her decision. ${ }^{27}$ Because there is no recipe or prescription for justice, we can never formulate or construct a 'just' law. But whilst justice is foreign to encapsulation, a decision still needs to be made. ${ }^{28}$ This decision might be in accordance with the law and thus legal, but not just. The moment of undecidability, although being a necessary stride in arriving at a 'just' decision, will not in itself bring about justice either, 'for only a decision is just'. ${ }^{29}$ To attain justice through law thus requires the (impossible) amalgamation of an incalculable experience with a calculable, rule governed construct. Ultimately, there can be no justice without a decision and no decision can effectively capture justice. This leads Derrida to arrive at the conclusion that a decision can never 'be said to be presently and fully just: either it has not yet been made according to a rule, and nothing allows us to call it just, or it has already followed a rule,.

With the third aporia, Derrida illustrates how the immediacy and urgency that characterise justice, impedes deliberative practice. Because the demand for justice is always immediate, it obstructs the horizon of knowledge, which is 'both the opening and the limit that defines either an infinite progress or a waiting and awaiting, ${ }^{31}$ The infinite demand for justice does not allow

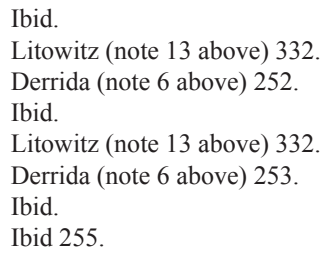


for a subsequent engagement with 'the infinite information and unlimited knowledge of conditions, rules or hypothetical imperatives that could justify it'. ${ }^{32}$ By making a decision, we bring an untimely halt to an attempt at rendering bottomless justice to the Other, which is why justice is always 'to come': '[Justice] remains by coming, it has to come, it is to come ... it deploys the very dimension of events irreducibly to come., ${ }^{33}$

These three interrelated aporias demonstrate why law is inaccessible to justice: trying to deposit an incalculable duty (justice) into calculable rules (law) is like trying to fit a square into a circle. But what is the reciprocity between law and justice? Whilst Derrida explicitly distinguishes law from justice, he does not place the two at counter-ends of a binary dualism. Derrida illustrates the reciprocal action through the notion of 'undeconstructability'. Both the deconstructability of law and the undeconstructibility of justice, makes deconstruction attainable. Deconstruction therefore subsists in the space that divides law, which as a construct will always be deconstructable, from the undeconstructability of justice. We thus see a symbiotic relationship ultimately ending in mutual reinforcement - 'Justice undermines law and law undermines justice, ${ }^{34}$ We also see a clear nexus between justice and deconstruction, in fact Derrida goes as far as saying 'deconstruction is justice' ${ }^{35}$ For the purposes of this article I will not further examine this statement on the several levels needed to do justice to Derrida's thought. My focus is rather on problematising and destabilising a legal system that's claim to authority rests on nothing but its own functioning and it is through deconstruction that we expose and resist the faults imbedded in the system.

\section{Reconceiving Deconstruction as the Philosophy of the Limit}

By renaming deconstruction the philosophy of the limit Cornell, 'driven by an ethical desire to enact the ethical relation', allows us to better comprehend the philosophical foundations of deconstruction and its implications for a legal system. ${ }^{36}$ The philosophy of the limit refocuses our attention on the limits that hinder philosophical understanding and subsequently highlights two aspects of deconstructive theory that are vital to comprehending philosophical perspectives on legal problems. Firstly, deconstruction seen as the philosophy of the limit reserves the possibility of ethical engagement within deconstructive thought. By juxtaposing a view of deconstruction as an exercise ultimately generating an 'unreconstuctable litter' with a notion of deconstruction as a philosophy that limits, Cornell illustrates that deconstructive tradition allows for the discovery and preservation of standards for ethical conduct and the capacity of deconstruction to advance the ethical relation is thus emphasised.

\footnotetext{
Ibid.

Ibid 256.

34 M Valverde 'Derrida's Justice and Foucault's Freedom: Ethics, History, and Social Movements' (1999) 24 Law and Social Inquiry 655, 659.

35 Derrida (note 6 above) 243.

36 Cornell (note 14 above).
} 
The focus of Cornell's project is rather on 'expos(ing) the quasi-transcendental conditions that establish any system, including a legal system as a system,. ${ }^{37}$ This shift in focus emphasises a 'beyond' intrinsic to any system, that which is excluded from the system.

Secondly, deconstruction seen as a limit captures the ineptness that inevitably accompanies any attempt to grasp meaning. In critiquing Hegelian idealism, Charles Pierce employs the notion of secondness to indicate that we will always be left with a residue after an attempt to conceptualise, something that 'resists', because we can never interpret reality in its totality. ${ }^{38}$ This restriction to a system of meaning emphasises the subjective nature of reality and impinges on our relationship to the Other, as it 'demands our attention to what is outside ourselves and our representational schema'. ${ }^{39}$ Understanding the sphere of secondness is thus foundational to any attempt at advancing the ethical relation to the Other.

This attempt to heed the call of the Other should however not be seen as an effort to incorporate that which is other into the system. There will always be an Other to the system, as the functioning of différance ${ }^{40}$ impedes any system from integrating its other into the system. A nonviolative relation to the Other is not founded in forced unity, but in the recognition of the Other's particularity and ensuing difference. Paradoxically, an instance of sameness emanates from this very recognition. Amidst this ethical asymmetry, we find phenomenological symmetry by recognising that the Other, also being an 'I' just as I am an 'I', is simultaneously different from me and the same as me. ${ }^{41}$ Unity stems from our singularity and this interplay between ethical asymmetry and phenomenological symmetry is pivotal to heeding the call of the Other. As Derrida explains, 'without the phenomenon of other as other no respect would be possible. The phenomenon of respect supposes the respect of phenomenality. And ethics, phenomenology, ${ }^{42}$

With this interpretation of the ethical relation, we firstly see another ethical dimension to Derrida's deconstructive thought. Derrida attempts to reserve the prospect of a nonviolative relationship by showing that the Other should be regarded as the 'unsayable', as 'one cannot speak of the ethical as the beyond to metaphysics other than in the language of ontology. ${ }^{43}$ Secondly, Derrida's insight requires that we acknowledge the ethical relation as an aspiration and not a possibility, as 'the possibility of the ethical lies in its impossibility; otherwise, the ethical would be reduced to the actual, to the totality of what

37 Ibid 1.

38 Ibid.

39 D Cornell 'Institutionalization of Meaning, Recollective Imagination and the Potential for Transformative Legal Interpretation' (1988) 136 Univ of Pennsylvania LR 1135, 1198.

40 Cornell describes differance as "the "truth" that "being" is presented in time and, therefore, there can be no all encompassing ontology of the "here" and "now". D Cornell Beyond Accommodation (1991) 108.

41 Cornell (note 14 above) 55.

42 J Derrida Signéponge (1984) 121.

43 Cornell (note 14 above) 83. 
is'. ${ }^{44}$ Deconstruction protects the ethical relation from being reduced to 'the mere Other of Ontology', an appropriation that denies the otherness of the other. Deconstruction then exposes the limit to the achievable. It is, as Cornell reconceptualises the practice, a philosophy that limits. This limit of impossibility, as with the impossibility of justice, does however not relieve us from our limitless responsibility:

There is [always] disruption of totality. The Other cannot be completely eliminated in any given representational system. The Other survives. In this sense, the ethical is a necessity as well as an impossibility - a necessity in that the remain(s) cannot totally be evaded even if they need not be heeded. The Other remain(s). The call to responsibility is prior to our subjectivity, prior to our choice. We may not answer, but we are not free to simply silence the call. ${ }^{45}$

In answering the question whether deconstruction enacts the ethical relation, Cornell thus reminds us that we ultimately enact the ethical relation through aspiration and not actualisation. ${ }^{46}$

\section{Veganism and Deconstruction}

In Comment ne pas manger - Deconstruction and Humanism, ${ }^{47}$ David Wood formulates various arguments to substantiate his assertion that, despite an attempt to address and advance the ethical relation to 'the animal' through the deconstruction of the (human) subject, Derrida's thought is haunted by a humanist predilection. For Wood, Derrida's critique of Heiddegerian thought as constrained by 'a certain anthropocentric or even humanist teleology ${ }^{48}$ is ironic and paradoxical because Derrida himself fails to recognise and advance the relation between (the) deconstruction (of the human subject) and vegetarianism.

Whilst I agree with Wood that there is deconstructive capacity inherent to our resistance to nonhuman sacrifice through physical consumption, I do not subscribe to the notion that we can oppose anthropocentric configurations by merely renouncing the consumption of flesh. Rather than commensurating deconstruction with vegetarianism, what is needed is a deconstruction of vegetarianism. My primary aspiration here is to expose the undercurrents of sacrifice and anthropocentrism that underlie vegetarianism and to illustrate why deconstruction, if recognised as a vehicle through which we respond to our ethical responsibility to (nonhuman) otherness, should rather be identified with veganism.

It needs to be noted from the onset that the scheme of domination that has come to be synonymous with the (human) subject spans the entire spectrum of our existence, with various institutions maintaining this ideology of

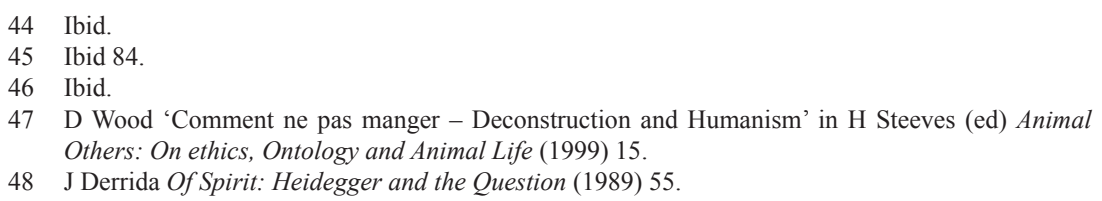


sacrifice. Derrida's objective of deconstructing the (human) subject as a being that sacrifices is obvious. One of the nuances to Derrida's deconstructive undertaking that might not be so apparent, is his concomitant exposure of the role of law as facilitator of this sacrificial behaviour. Our anthropocentric cultural constructs cannot be separated from the (legal) system that allows for the 'non-criminal putting-to-death' of animals, as the law (being a human construct) will reproduce and perpetuate prevailing social structures. To this extent, any rigid separation between our aspiration towards 'formal' justice in the public sphere and 'informal' justice in the sphere of socio-ethical relations will ultimately prove to be fictitious, as sustainable transformation in the one sphere is dependent on transformation in the other. ${ }^{49}$ As any destabilisation of species hierarchy will thus inevitably be observed by the law, our resistance of anthropocentric social configurations also exposes and resists the anthropocentric character of the law. This reciprocity between and challenge to the private/public division needs to be borne in mind as I advance veganism as a practice that deconstructs anthropocentrism. But let me first sketch the background to Wood's critique on Derrida.

\section{(a) The (human) subject and sacrifice}

In an interview with Jean-Luc Nancy entitled " Eating Well”, or the Calculation of the Subject ${ }^{50}$ Derrida deconstructs the notion of subjectivity by engaging with the question 'Who comes after the subject?'. Derrida destabilises the question from the onset and broadens the scope of his deconstructive undertaking (to include 'the animal') by alluding to the segregative nature of the pronoun 'who' as facilitator of a problematic 'human'/'animal' dualism. Despite Nancy's effort to delineate the 'who' in his question as a sphere transcending subjectivity, as a "place "of the subject" that appears precisely through deconstruction itself, ${ }^{51}$ Derrida remains adamant that the "substitut[ion] [of] a very indeterminate "who" for a "subject" overburdened with metaphysical determinations is perhaps not enough to bring about any decisive displacement' of subjectivity. ${ }^{52}$

Derrida then goes on to draw a nexus between the 'who' and the notion of 'sacrifice' and it is here where Derrida, according to Wood, 'parts company with vegetarianism'. Derrida starts off by saying:

I would still try to link the question of the 'who' to the question of 'sacrifice'. The conjunction of 'who' and 'sacrifice' not only recalls the concept of the subject as phallogocentric structure, at least according to its dominant schema: one day I hope to demonstrate that this schema implies carnivorous virility. ${ }^{53}$

50 J Derrida \& J-L Nancy "'Eating well”, or the Calculation of the Subject: An Interview with Jaques Derrida' in E Cadava (ed) Who Comes After the Subject (1991) 96.

51 Ibid 98.

52 Ibid 100.

53 Ibid 113. 
Derrida depicts this schema of domination in 'the whole canonised or hegemonic discourse of Western metaphysics or religions, ${ }^{54}$ which he calls carnophallogocentrism, as:

[a] matter of discerning a place left open, in the very structure of these discourses (which are also 'cultures') for a noncriminal putting to death. Such are the executions of ingestion, incorporation, or introjections of the corpse. An operation as real as it is symbolic when the corpse is 'animal'.

Wood focuses on the difference between symbolic and actual sacrifice and argues that Derrida 'interiorize[s] the actual eating of animals inside the symbolic eating of anything by anyone', thereby convoluting this distinction in an attempt to amalgamate the two manifestations of sacrifice. ${ }^{56}$ As a degree of symbolic sacrifice seems inevitable to Wood, he argues that this superficial amalgamation allows us to simultaneously accept this fate and congruently evade our ethical responsibility to take steps that could eradicate actual sacrifice. Wood argues as follows:

First [Derrida] assimilates - there is no other word for it - real and symbolic sacrifice so that real sacrifice (killing and eating flesh) becomes an instance of symbolic sacrifice. With this change of focus, the question of eating (well) can be generalized in such a way as to leave open the question of real or symbolic sacrifice. And to the extent that in this culture sacrifice in the broad (symbolic sense) seems unavoidable, there would seem to be little motivation for practical transformations of our engagement in sacrificial behaviour. ${ }^{57}$

The practical transformation that Wood refers to is of course the ethically motivated espousal of a vegetarian existence. Vegetarianism, Wood argues, can be seen as a deconstructive practise insofar as it 'can become a finite symbolic substitute for an unlimited and undelimitable responsibility - the renegotiation of our Being-toward-other-animals'. ${ }^{58}$ Wood's assertion is thus that vegetarianism circumvents real sacrifice and, as the symbolic manifestations of sacrifice are inescapable, vegetarianism thus provides an adequate pragmatic foundation for advancing the ethical relation to the nonhuman Other. And this is where his argument becomes problematic. It is a dangerous and violent appropriation to place only the actual killing of a nonhuman animal in the register of real sacrifice and all other forms in the register of symbolic and consequently unavoidable sacrifice. Here, I would like to comment on Wood's interpretation of Derrida's exposition of the inevitability of symbolic sacrifice and his assertion that vegetarianism proliferates resistance to anthropocentric schemata of domination.

\section{(b) Symbolic sacrifice as secondness}

In his interview with Nancy, Derrida argues that a sort of symbolic violence is a general inevitability of life and that 'vegetarians, too, partake of animals, 
even men. They practice a different mode of denegation'. ${ }^{59}$ Derrida has elsewhere argued that 'a certain cannibalism remains unsurpassable' and that he consequently does not believe in 'absolute vegetarianism':

[V]egetarians, like everyone else, can also incorporate, symbolically, something living, something of flesh and blood - of man and of God. ${ }^{60}$

These assertions, I believe, are consistent with Derrida's argument that the ethical relation is an impossible possibility, impossible because we cannot condense the ethical to the actual and thereby realise the relation. As is the case with (the impossibility of) justice, this does however not relieve us of our ethical responsibility to strive towards an ethical relation to the nonhuman Other. Clearly, the inevitable violence and denegation that Derrida speaks of does not refer to the actual killing of animals for consumption, or to any form of violence that can be avoided for that matter.

The inevitability lies in the impossible, that which always resists our attempt to heed the call of the Other. Symbolic sacrifice, therefore, dwells in the sphere of secondness; it is the manifestations of sacrifice that resists concretisation, encapsulation and eradication. This form of sacrifice cannot be concretised because there will always be a surplus to our system of meaning that resists an attempt to interpretively harmonise any 'sign ${ }^{, 61}$ with the suffering. This manifestation of sacrifice cannot be semeiotically encapsulated either because there is no enclosed circle in which interpretation of the sacrifice takes place, 'the sign itself always points us to another sign beyond the repetition implicit in self-reference. ${ }^{62}$ This sacrifice is analogous to what Cornell refers to as 'the irreducible exteriority of suffering'; neither past nor future instances of this manifestation of sacrifice can be 'interpreted away. ${ }^{63}$ Symbolic sacrifice is the residue that evades internment by any system of signs. With this in mind, let me now turn to the problematical aspects of Wood's assertion that vegetarianism deconstructs humanist predilections.

\section{(c) The anthropocentric predilection of vegetarianism}

The argument that vegetarianism is a form of deconstruction that resists actual sacrifice and anthropocentric configurations falls short on two levels. Firstly, we need to clearly delineate the disparity between symbolic and actual sacrifice. If we are to subscribe to my argument that symbolic sacrifice stems from inevitable violation and real sacrifice from violative conduct that can be avoided, we will see why vegetarianism does not circumvent real sacrifice.

60 J Derrida \& E Roudinesco For what Tomorrow (2004) 67-8.

61 For Pierce, a 'sign' is something that carries extended meaning, something through which we 'know something more'. See T Zick 'Cross Burning, Cockfighting, and Symbolic Meaning: Toward a First Amendment Ethnography' (2004) 45 William and Mary LR 2261, 2330.

62 Cornell (note 39 above) 1198.

63 Ibid 1170. 
For the animals that produce the by-products that form part of a vegetarian diet, life is anything but natural and nonviolative. After being debeaked to avoid the cannibalistic behaviour that would otherwise ensue from the overcrowded conditions, layer hens are confined to battery cages so small that they are denied even the most basic desire to spread their wings. Layer hens endure these circumstances until they are no longer physically able to produce enough eggs to outweigh the costs of keeping them alive. They are then usually sold to low-income households for home slaughter or killed. ${ }^{64}$ Sadly, the reality that accompanies the dairy that we consume is not any rosier. Predestined for a lifetime of pregnancies and milking, cows are fed an artificially manipulated diet and hormones that promote lactation, resulting in ten times the milk production of a cow under natural conditions. After an abnormally short life of three to five years, the cows are sent to the slaughterhouse where they are killed and processed into meat for consumption. ${ }^{65}$ It is hard to accept Wood's implicit argument that the sacrifice typifying these animals' lives are merely symbolic. The sacrifice is very real and can, more importantly, be avoided by adopting a vegan lifestyle.

There are some that may argue that the lives of these animals need not be so violative, that we can circumvent these harsh conditions by rearing animals in 'free-range' environments and implementing welfare strategies to better their overall life conditions. It is not my goal to address the false promises and pragmatic impracticalities of these 'free-range' conditions and welfarist approaches. ${ }^{66}$ I'd rather like to demonstrate that, even if we accept the possibility of raising and utilising these animals in a way that is completely natural and nonviolative, vegetarianism as a form of deconstruction will still fail to resist anthropocentric configurations.

Secondly, vegetarianism is underscored by the notion that human beings have the right to freely take and use the by-products of nonhuman animals as we see fit. Granted that nonhuman animals are not directly killed for this purpose, they still occupy a dimension as sacrificial beings; they are seen as means to a (human) end. This anthropocentric approach places man in the position of the dominant subject with the nonhuman animal being denounced to subservient Other. No degree of 'humane' treatment or loving affection can eliminate this anthropocentrism inherent to vegetarianism. The slave working under reasonable or even plush conditions is still exactly that: a slave, an individual having no other alternative than being servant to her master. The argument that vegetarianism can deconstruct and subsequently resist our anthropocentric way of dealing with and thinking about other animals is consequently internally paradoxical. It is true that: 
carophallogocentrism is not a dispensation of Being toward which resistance is futile; it is a mutually reinforcing network of powers, schemata of domination, and investments that has to reproduce itself to stay in existence. ${ }^{67}$

These schemata of domination can and should furthermore be resisted, but by attempting to resist one anthropocentric institution with another one, we run the risk of perpetuating the system we seek to eradicate.

\section{CONCLUSION}

This article should by no means be misconstrued as a critique of animal welfarism or vegetarianism as such. It should go without saying that vegetarianism is indeed a more ethical way of being than a carnivorous existence, resisting (if nothing else) the killing of so many of our fellow earthlings. By exposing the anthropocentric values woven into the supposedly unprejudiced fabric that constitute vegetarianism, I have merely tried to argue that it would be philosophically inconsistent to associate vegetarianism with the deconstruction of carnophallogocentrism as there can fundamentally be no ensuing displacement of the (human) subject as dominant figure.

My primary aspiration was to advance veganism as a way of being that allows us to move towards the enactment of the ethical relation to the nonhuman Other. To this end, I started off by examining the interaction between law, justice and deconstruction. Through Derrida's conceptualisation of justice as a state of puzzlement that cannot be resolved, we saw that justice serves as a limit to any system of law. The second part of this article was devoted to an engagement with Cornell's project of reconceiving deconstruction as the philosophy of the limit, a project that exposed the ethical force behind deconstruction and protected the ethical relation from being degenerated into symmetry and the Other being denied her otherness. The philosophy of the limit also showed us that the ethical relation can never be realised, it remains an impossible possibility. The question then, is what mode of being will enable me to foster a nonviolative relationship to the (nonhuman) Other? In answering this question, I exposed the inherent anthropocentric and sacrificial character of vegetarianism and advanced veganism as a way of being that allows us to criticise and resist subjugation of the (nonhuman) Other.

Ethical philosophy, it seems, fulfils an important critical function. It exposes ill-conceived formulations and schematisations and depicts ensuing limitations. No one can claim a just existence or actualise the ethical relation to the nonhuman Other, not even the vegan. Justice (and the realisation of the ethical relation) might, sadly, indeed only come in the next world. But it simultaneously also poses a test to our humanity, daring us to engage in a battle that is both a necessity and an impossibility. 